\title{
Medios de comunicación públicos y participación
}

\author{
Francisco Campos Freire \\ Universidad de Santiago de Compostela
}

Antonio Loriguillo-López

Universitat Jaume I

\section{Referencia de este artículo}

Campos Freire, Francisco y Loriguillo-López, Antonio (2021). Medios de comunicación públicos y participación. En: adComunica. Revista Científica de Estrategias, Tendencias e Innovación en Comunicación, $\mathrm{n}^{0} 21$, 21-24. DOI: http://dx.doi. org/10.6035/2174-0992.2021.21.2

El enfoque de la participación es uno de los aspectos fundamentales hacia el que orientan actualmente la gestión de su valor público varias de las principales corporaciones europeas de medios audiovisuales públicos. Así, con el objetivo fundamental de dotar de forma a un nutrido panorama, tan diverso como cuantioso, se incluyen en la sección Informe de este número 21 de la revista adComunica siete investigaciones que abordan algunos de los aspectos fundamentales de la relación entre audiovisual público y participación ciudadana.

En el primero de los artículos, Marius Dragomir se embarca en la búsqueda de una definición precisa del concepto que no ocupa: la participación ciudadana en medios de comunicación públicos. Mediante una recopilación de las últimas tendencias en interacción con sus públicos, el autor prevé que los medios públicos no conseguirán hacerse con nuevos seguidores (en especial, entre las franjas demográficas más jóvenes) sin antes convertirlos en el verdadero centro de una red de plataformas 
de distribución de sus contenidos. Y advierte: sin una ciudadanía participando activamente, los medios públicos corren el riesgo de convertirse en obsoletos.

A continuación, Anne-Sofie Vanhaeght y Karen Donders emplean modelos de la teoría política en democracia para poner en duda la asumida ecuación de que más participación equivale a un mejor servicio a la sociedad. Este audaz enfoque, especialmente sugerente en el estudio académico de los medios de comunicación públicos, lleva a sus autoras a sugerir una mayor resolución a los medios públicos a la hora de integrar la participación entre sus estrategias comunicativas, algo que pasa por la mayor toma de riesgos derivados a una apertura mayor hacia las necesidades diversas de todos los grupos que componen su audiencia.

En el tercer artículo, Martín Vaz Álvarez, César Fieiras-Ceide y Miguel Túñez-López proponen una aproximación, basada en entrevistas en profundidad con sus responsables de innovación, a las experiencias de co-creación llevadas a cabo por parte de varias radiotelevisiones públicas europeas. Su análisis concluye que, pese a sus diferencias superficiales, el empuje e iniciativa demostrados por los PSM europeos encuentran complicado crear vínculos transversales y de calidad con sus audiencias.

La cuarta propuesta, presentada por Clide Rodríguez Vázquez, María Magdalena Rodríguez Fernández y Tania Fernández Lombao, pone a prueba el grado de compromiso de las radiotelevisiones públicas de España, Portugal y Francia con sus audiencias a través de un estudio de sus mecanismos de participación. Así, a través de un análisis de contenido de los documentos de responsabilidad social corporativa de los distintos entes públicos, se evidencia que las estrategias creativas a la hora de interactuar con sus públicos quedan en un segundo plano, precedidas por los portales web y las secciones de comentarios como los instrumentos predilectos de interacción.

La propuesta de Bethlem Boronat Clavijo, por su parte, versa sobre el derecho al acceso a los medios de comunicación públicos. Pese a la eminencia de las estrategias de fomento para la participación ciudadana en los entes públicos, esta herramienta pasa desapercibida pese a su potencial vertebrador del diálogo en la esfera social. Tras una comparativa entre la legislación de España, Comunidad de Madrid, Italia, Francia y Portugal, la autora propone un modelo que siga algunas buenas prácticas basadas en la publicidad del derecho al acceso, la simplificación burocrática para la ciudadanía interesada en él, la ampliación de los formatos que tienen cabida en la ley o la creación de un órgano independiente para su arbitraje, entre otros.

Rubén Rivas-de-Roca nos presenta a continuación un artículo donde realiza un análisis en profundidad los modelos participativos de dos culturas periodísticas ajenas mediante los casos de estudio de Andalucía (RTVA) y de la región de Berlín y Brandeburgo (RBB). El estudio de estos dos entes públicos, implicados en el reto de la renovación urgido por el auge de la participación, permite al autor constatar 
las disonancias entre los contextos mediáticos de cada caso: los mecanismos más personalizables de RBB frente a la pasividad en redes sociales de RTVA.

La última aportación de esta sección, de Cristina Zurutuza-Muñoz e Inés García Herrera, nos acerca a la integración de la participación ciudadana en localidades de tamaño de población reducido a través del caso de estudio de los municipios de la Comarca Campo de Daroca (Zaragoza). Gobernados en régimen de concejo abierto, las dinámicas comunicativas de estos núcleos de población están caracterizadas por la proximidad y la horizontalidad entre ciudadanos y alcaldías. Así, los medios de comunicación quedan en un segundo plano, mientras que las herramientas comunicativas empleadas en el día a día entre vecinos se asemejan sobremanera a la comunicación interna de una corporación.

Finalmente, en la sección Tribuna se recogen los puntos de vista de tres profesionales estrechamente vinculados a la radiotelevisión pública y a sus contenidos digitales. Así, las contribuciones de Isaías Blázquez (CMMedia), Lontzo Sainz (EITB), Fernando Ojea (CIRCOM) nos permiten acercarnos a los procesos de innovación que se están llevando a cabo en los medios de comunicación regionales, actores imprescindibles en el escenario de la participación ciudadana.

\section{Reconocimiento de investigación}

Esta introducción y la coordinación de este monográfico forman parte de las actividades de los proyectos de investigación «Participación ciudadana y medios de comunicación públicos. Análisis de experiencias de co-creación audiovisual en España y en Europa» (ref. RTI2018-093649-B-I00) y «Nuevos valores, gobernanza, financiación y servicios audiovisuales públicos para la sociedad de Internet: contrastes europeos y españoles» (RTI2018-096065-B-I00) del Programa Estatal de España de I+D+I orientado a los Retos de la Sociedad del Ministerio de Ciencia e Innovación del Gobierno de España /AEI/FEDER. 
